\title{
Stability and Thermal Performance of Silica Nanofluid in Water Block Heat Sink
}

\author{
Rahmah Zulkeflee and Hussin Mamat \\ School of Aerospace Engineering, Universiti Sains Malaysia, Engineering Campus, \\ 14300 Nibong Tebal, Pulau Pinang, Malaysia \\ *Corresponding author: hussinm@usm.my
}

Published online: 25 December 2019

To cite this article: Zulkeflee, R. \& Mamat, H. (2019). Stability and thermal performance of silica nanofluid in water block heat sink. J. Phys. Sci., 30(Supp. 2), 1-11, https:// doi.org/10.21315/jps2019.30.s2.1

To link to this article: https://doi.org/10.21315/jps2019.30.s2.1

\begin{abstract}
Thermal performance has become one of the main issues in electronic industries in line with prevailing development. Conventional working fluid such as distilled water (DI) often used by electronic devices has some shortcomings on the efficiency of transferring heat for cooling purposes. Hence, nanofluid is a promising alternative as it will be able to help improvising and more competent than subsist working fluid. In this experiment, water-based nanofluid with gum Arabic (GA) as surfactant is used. The main purpose of this study is to investigate the effect of $G A$ and different volume concentrations of silica nanoparticles in DI on thermal performance and stability of nanofluids. Various volume percentage (vol\%) of nanoparticles ( 0.1 vol\%, 0.3 vol\% and 0.5 vol\%) were used and nanofluid was dispersed using sonication process for 20 min. Temperature distribution on heat sink water block with range of flow rates $\left(0.05 \mathrm{~m}^{3} \mathrm{~h}^{-1}\right.$ to $\left.0.1 \mathrm{~m}^{3} \mathrm{~h}^{-1}\right)$ and heating power of $20 \mathrm{~W}$ was used to determine the efficiency of nanofluid as heat transfer fluids. The result shows that fluid contact surface temperature reduced with addition of silica at various flow rates as compared to that of distilled water. The thermal resistance of nanofluids reduced at all flow rates, reduction of $20 \%$ in thermal resistance is observed at all flow rate compared to DI. Higher heat transfer coefficient (HTC) is observed for nanofluids compared with DI because of their higher thermal conductivity. Comparison on experimental data with theoretical data calculated based on Maxwell theory indicated that thermal conductivity increased with increasing silica content with more significant data shown by experimental result. Thermal conductivity enhancements increased with increasing silica concentration in nanofluids. Finally, according to the results, it can be claimed that silica nanofluid can be introduced as an alternative fluid in heat transfer system.
\end{abstract}

Keywords: Silica nanofluid, stability, heat transfer, thermal conductivity, distilled water 


\section{INTRODUCTION}

Heat transfer in industry has become more intense and demanding worldwide as it is become one of the most crucial tasks that can enhance the efficiency of heat transfer devices. Fluid with the ability to transmit abundant amount of heat either into the system or remove from the system with slight amount of temperature difference is known as heat transfer fluid. One of the heat transfer developments is the dispersion of the nanoparticles in a base fluid, known as nanofluids. ${ }^{1}$ Previous studies had been a major stepping stone in solving limitations faced by conventional working fluid by showing that dispersion of metals or metal oxides have higher potential in heat transfer industry. Nanofluids are exciting new materials that came into existence due to innovative idea involved in this research. ${ }^{2}$ The evolution of solid particles leads to nanometric size particles $(<100 \mathrm{~nm})$ known as nanoparticles with the ability to significantly affect thermal performance of a base fluid. ${ }^{3}$

The main goal of nanofluids is to achieve the highest possible value of thermal conductivity at the smallest possible concentration of nanoparticles. Previous works have showed that the nanofluids exhibited higher thermal conductivity even for low concentration of suspended nanoparticles. ${ }^{4,5}$ Performance of the nanofluids is majorly influenced by type of base fluid, size and shape of particles, particles concentration, temperature and shearing time. ${ }^{6}$ The stability of nanofluids is important for cooling applications. Stability is directly related to viscosity, thermal conductivity and other thermo-physical properties of nanofluids. ${ }^{7}$ The most important aspects to be considered in stability is the tendency of nanofluid to sediment and aggregate. Aggregation or coagulation happens due to the strong force of van de Waals attraction among nanoparticles and it may cause clogging and do not show consistent cooling performance. ${ }^{8}$ Addition of surfactant will help in dispersibility and stability of nanofluid without disrupting the internal electronic structure as it will decrease the interfacial surface tension created by van der Waals. $^{7}$

In the present work, we studied on the stability of silica nanofluid using three types of surfactants, namely gum Arabic (GA), dodecylbenzenesulphonic acid (DBSA) and chinese ink (CI). To confirm the stability of the nanofluids, visual inspection was carried out for 30 days. After confirming the results, the nanofluids with different nanoparticles concentrations $(0.1 \mathrm{vol} \%, 0.3 \mathrm{vol} \%$ and $0.5 \mathrm{vol} \%)$ were prepared using the best surfactant. Nanofluids were prepared using two step method and nanofluid was dispersed using sonication process for $20 \mathrm{~min}$. Thermal conductivity of the nanofluids was measured and stability of the nanofluids was inspected. 


\section{EXPERIMENTAL}

\subsection{Materials}

Commercial silica with average size of $12 \mathrm{~nm}$ was purchased from Sigma Aldrich. Distilled water (DI) was used as a base fluid. GA, DBSA and CI were used as surfactants in the present study. CI was purchased from Winsin Trading Sdn. Bhd. DBSA was supplied by Acros Organics. Commercial type of GA was purchased from grocery shop and all these surfactants were used without modification.

\subsection{Nanofluids Preparation Method}

The two-step method was used to prepare silica nanofluids using distilled water as the base fluid. Silica with volume concentrations of $0.1 \mathrm{vol} \%$ was prepared using surfactant such as DBSA, GA and CI.

The mass of the nanoparticles for each volume concentration was estimated using the density of the nanoparticles and base fluid, as given in the Equation 1:

$$
\varphi=\frac{\frac{m_{n}}{\rho_{\mathrm{n}}}}{\frac{m_{n}}{\rho_{\mathrm{n}}}+\frac{m_{\mathrm{f}}}{\rho_{\mathrm{f}}}}
$$

where $\varphi, \mathrm{m}_{\mathrm{n}}, \mathrm{m}_{\mathrm{f}}, \rho_{\mathrm{n}}$ and $\rho_{\mathrm{f}}$ refer to volume fraction, the mass of nanoparticles, the mass of base fluid, the density of nanoparticle, and the density of the base fluid, respectively.

Nanofluid with silica without surfactant was prepared by dispersed silica in DI. The weighed nanoparticle was mixed with DI and stirred by hand for $30 \mathrm{~s}$. The mixture then underwent probe sonication (model UP200s) for 20 min under 0.5 cycle and $50 \%$ amplitude to obtain uniform nanoparticle dispersion. ${ }^{9}$ After sonication, the nanofluids are filled into $30 \mathrm{ml}$ bottles to observe the stability responses of the nanofluid. The prepared nanofluids were kept under visual surveillance for 30 days so as to investigate the stability of the samples.

\subsection{Characterisation and Analysis}

The thermal conductivity of nanofluids was carried out by using KD2 Pro thermal property analyser (Decagon Devices Inc., United States). This measurement was done at room temperature (about $24^{\circ} \mathrm{C}$ ). Three measurements were taken at each volume concentration to get the average value. The value measured was then 
compared with some correlations suggested from past researches. Based on the experiments, thermal conductivity enhancement is defined as in the following equation:

$$
\text { Thermal conductivity enhancement }(\%)=\frac{\mathrm{k}_{\mathrm{nf}}-\mathrm{k}_{\mathrm{bf}}}{\mathrm{k}_{\mathrm{bf}}} \times 100
$$

where $\mathrm{k}_{\mathrm{nf}}$ and $\mathrm{k}_{\mathrm{bf}}$ are thermal conductivity of nanofluid and base fluid, respectively.

\section{$2.4 \quad$ Experimental Set-up}

The schematic diagram of the experimental set-up is shown in Figure 1. The process began by filling the storage tank with the working fluid at standard room temperature of $25^{\circ} \mathrm{C}$. A pump with flow rate of $6001 \mathrm{~h}^{-1}$ was used to transfer the fluid out of the storage tank, through a flowmeter, and into the RAM water block which was attached to the heating element. The working fluid absorbed heat from the heat sink. A flow meter was used to measure the working fluid flow rate and the flow rate was adjusted by restricting the fluid flow with ball valve. An aircooler (240 mm long heat sink with fins) was used to perform cooling process of the working fluid before it flowed back to the storage for recirculation. Two units of ultrasonic pressure transmitters (model: PT5404) were connected at the cooling fluid inlet and outlet to measure the gauge pressure difference and the signal from transmitters were sent to multi-function display for monitoring analogue standard signals (model DX2042) to show the value of the gauge pressure measured.

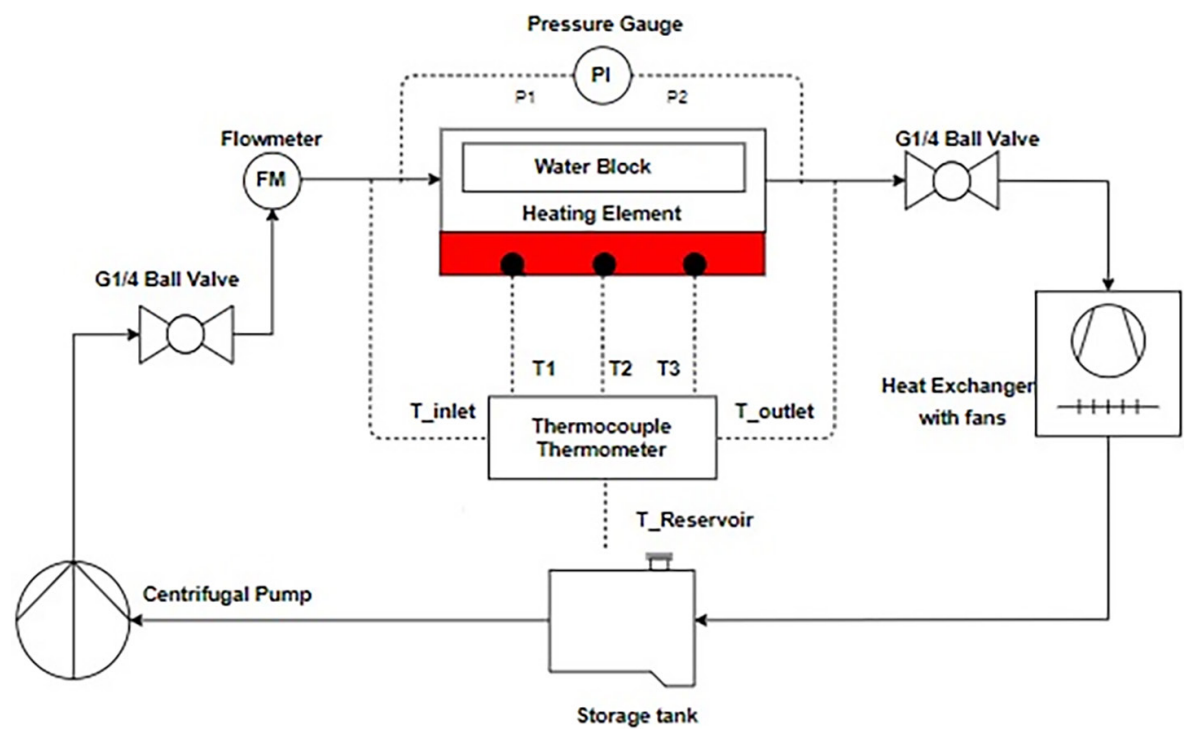

Figure 1: Schematic diagram of experimental set-up. 


\subsection{Data Analysis}

Thermal resistance $\left(\mathrm{R}_{\mathrm{th}}\right)$ of fluid is the property of fluid to resist heat flow whether to be absorb or released. ${ }^{10}$ Equation 3 is used to measure the thermal resistance of the nanofluids:

$$
\mathrm{R}_{\mathrm{th}}=\frac{\mathrm{T}_{\mathrm{b}}-\mathrm{T}_{\mathrm{nfin}}}{\dot{\mathrm{Q}}}
$$

where $T_{n f, i n}$ is the temperature of nanofluid entering the heat sink.

Base temperature $\left(T_{b}\right)$ of heat sink in Equation 4 is highly depending on the base of heat sink average temperature $\left(T_{\text {avg }}\right)$ and base area $\left(A_{b}\right)$ from the experiment.

$$
\begin{aligned}
& \mathrm{T}_{\mathrm{b}}=\mathrm{T}_{\mathrm{avg}}-\left(\frac{\dot{\mathrm{Q}} \mathrm{H}_{\mathrm{b}}}{\mathrm{k}_{\mathrm{hs}} \mathrm{A}_{\mathrm{b}}}\right) \\
& \mathrm{A}_{\mathrm{b}}=\mathrm{L}_{\mathrm{n}}\left(\mathrm{W}_{\mathrm{ch}}+\mathrm{W}_{\text {fin }}\right)
\end{aligned}
$$

In Equations 4 and 5, $\mathrm{k}_{\mathrm{hs}}$ is the heat sink thermal conductivity, $\mathrm{L}$ stands for heat sink length, $\mathrm{n}$ is the number of grooves, $\mathrm{W}_{\mathrm{ch}}$ is the width of heat sink, $\mathrm{W}_{\mathrm{fin}}$ is the width of the fin, and $\dot{Q}$ is the heat dissipation from heater.

The convective heat transfer coefficient (HTC) of the water block is determined with the following equation:

$$
\mathrm{HTC}=\frac{\dot{\mathrm{Q}}}{\mathrm{A}_{\mathrm{cs}}\left(\mathrm{T}_{\mathrm{cs}}-\mathrm{T}_{\mathrm{mn}, \mathrm{nf}}\right)}
$$

The mean temperature of the nanofluid $\left(\mathrm{T}_{\mathrm{mn}, \mathrm{nf}}\right)$ is the mean temperature of inlet and outlet. The mean temperature is determined by Equation 7 :

$$
\mathrm{T}_{\mathrm{m}, \mathrm{nf}}=\frac{\mathrm{T}_{\mathrm{nf}, \mathrm{in}}+\mathrm{T}_{\mathrm{nf}, \mathrm{out}}}{2}
$$

Many theories have been developed to compute the thermal conductivity of twophase materials based on the thermal conductivity of the solid and the liquid and their relative volume fractions. In 1881, Maxwell proposed a model, shown in Equation 8, to estimate the effective thermal conductivity of a solid-liquid mixture having spherical particles: ${ }^{11}$ 


$$
\frac{\mathrm{k}_{\mathrm{nf}}}{\mathrm{k}_{\mathrm{f}}}=\left[\frac{\mathrm{k}_{\mathrm{p}}+2_{\mathrm{kf}}-2\left(\mathrm{k}_{\mathrm{p}}-\mathrm{k}_{\mathrm{f}}\right) \varepsilon}{\mathrm{k}_{\mathrm{p}}+2_{\mathrm{kf}}+\left(\mathrm{k}_{\mathrm{p}}-\mathrm{k}_{\mathrm{f}}\right) \varepsilon}\right]
$$

where $\mathrm{k}_{\mathrm{nf}}$ is the effective thermal conductivity, $\mathrm{k}_{\mathrm{p}}$ is the thermal conductivity of nanoparticle, $\mathrm{k}_{\mathrm{f}}$ is the thermal conductivity of nanofluid and $\varepsilon$ is the particle volume fraction in the suspension.

\section{RESULTS AND DISCUSSION}

\subsection{Stability of Silica Nanofluid}

Visual inspection of silica nanofluids using DI as the base fluid is shown in Figure $2(\mathrm{a}-\mathrm{d})$. The addition of surfactant is based on $1000 \mathrm{ppm}$ where $1 \mathrm{~g}$ of surfactant was added into $1000 \mathrm{ml}$ of base fluid. A 0.1 vol\% silica nanoparticles were used in the nanofluid formulation. Silica nanofluid in Figure 2(a) is used as a control. Silica nanofluid dispersed in DI without any surfactant showed no sedimentation until day 15. Silica nanofluids with CI and DBSA showed sedimentation after 12 days and 1 day, respectively. On the other hand, no obvious sedimentation was observed for silica nanofluid with GA up to 30 days of observation. The addition of GA surfactant in silica nanofluids is observed able to improve the stability of nanofluid. This phenomenon can be explained by looking at the function of GA, where it hinders the interaction between the particles in the suspension and prevent agglomeration. Figures $3(\mathrm{a}$ and $\mathrm{b}$ ) show the visual inspection of 0.1 vol\% silica nanoparticles with GA surfactant for day 1 and day 30, respectively. It is observed that nanofluids with silica and GA are visually homogeneous indicating the nanofluids are stable for a long period, shown in Figure 3(b).

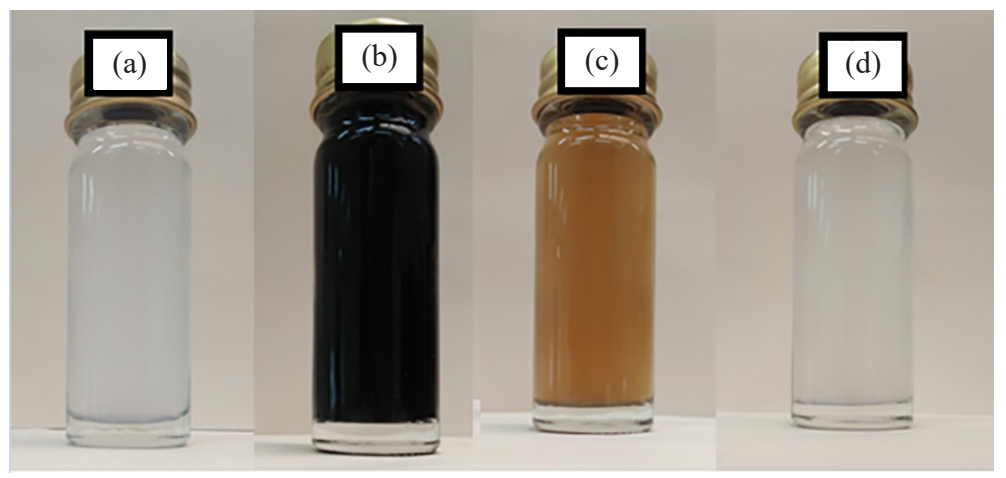

Figure 2: Nanofluids (at day 1) with (a) silica (without surfactant), and silica nanofluids with surfactants (b) CI, (c) DBSA, and (d) GA. 

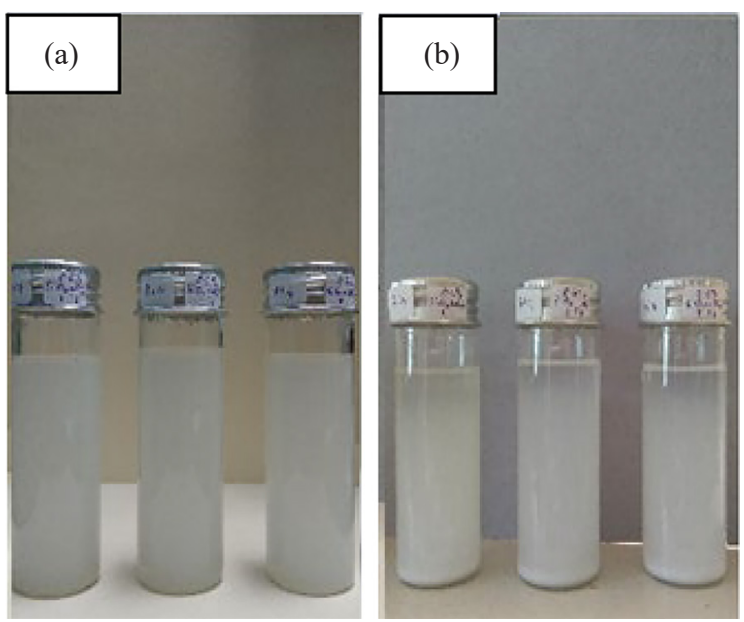

Figure 3: Visual inspection of 0.1 vol $\%$ silica nanofluids using distilled water as the base fluid for (a) day 1, and (b) day 30 .

\subsection{Heat Sink Base Temperature}

Figure 4 shows heat sink based temperature DI (without surfactant) and 0.1 vol\% of silica nanoparticles dispersed in DI and GA as the surfactant and flow rates of $0.05 \mathrm{~m}^{3} \mathrm{~h}^{-1}, 0.075 \mathrm{~m}^{3} \mathrm{~h}^{-1}, 0.1 \mathrm{~m}^{3} \mathrm{~h}^{-1}$ were used in the experiment. With addition of silica, the fluid contact surface temperature reduced compared to that of DI at various flow rates. It is found that base temperatures decreased at higher flow rates. This is because the heat from the heating element had been transferred by the fastmoving fluid before it accumulated in the RAM water block. Nanofluid with higher thermal conductivity compared to DI, able to transfer the heat to surrounding faster than DI even at high flow rates.
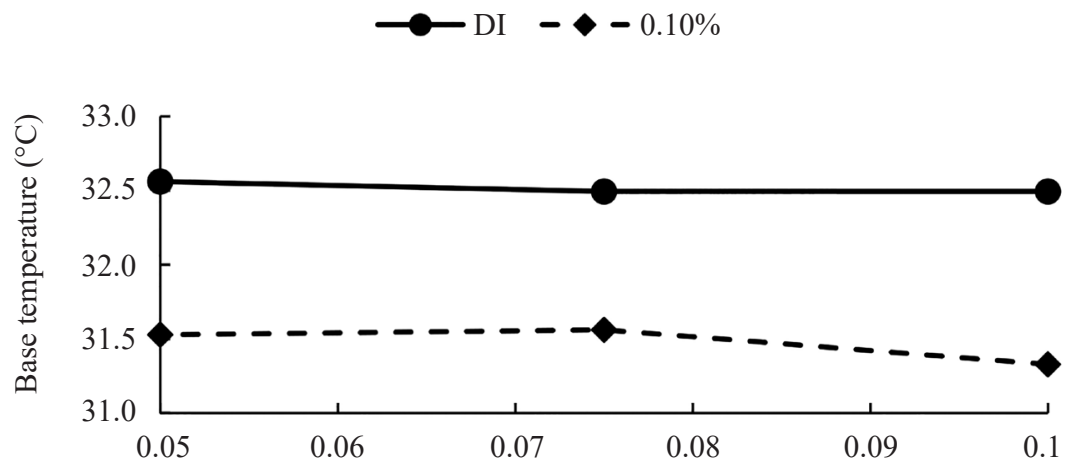

Figure 4: Heat sink base temperature for DI and the nanofluids at $20 \mathrm{~W}$. 


\subsection{Thermal Resistance}

Figures 5 and 6 show the graph of thermal resistance and heat transfer coefficient (HTC) of DI and nanofluids in a heat sink with $20 \mathrm{~W}$ level of power and flow rate of $0.05 \mathrm{~m}^{3} \mathrm{~h}^{-1}, 0.075 \mathrm{~m}^{3} \mathrm{~h}^{-1}$ and $0.1 \mathrm{~m}^{3} \mathrm{~h}^{-1}$. Thermal resistance of nanofluids reduced about $20 \%$ at $0.05 \mathrm{~m}^{3} \mathrm{~h}^{-1}, 0.075 \mathrm{~m}^{3} \mathrm{~h}^{-1}$ and $0.1 \mathrm{~m}^{3} \mathrm{~h}^{-1}$ flow rate compared with DI. Lower thermal resistance indicates higher heat transfer from the RAM water block to the nanofluid. Based on the graphs, thermal resistance was found to decrease with the increasing value of flow rate. Higher flow rate will lead to less time for the nanofluid to pass through the heat sink channels. Previous works have investigated silica-water nanofluid. ${ }^{12,13}$ They reported that thermal resistance decreased by $55.27 \%$ and $20 \%$ with addition of silica in water, respectively. This result shows the potential of using silica nanofluids to replace the conventional fluid for heat sink application.

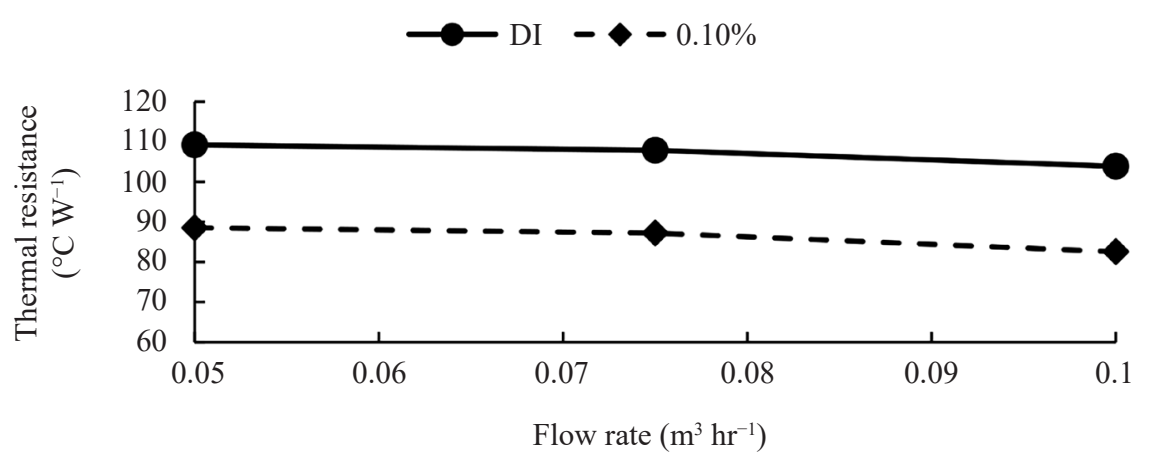

Figure 5: Thermal resistance of DI and nanofluids at a constant power (20 W).

The HTC of the heat sink operated with DI and silica nanofluids was analysed at different flow rates. Figure 6 shows that HTC increased with the increase of flow rates. A slight decrease at $0.075 \mathrm{~m}^{3} \mathrm{~h}^{-1}$ can be due to certain unavoidable glitches during experimental procedure. Slightly higher HTCs is observed for nanofluids compared to DI because of their higher thermal conductivity. The maximum HTC was found for the nanofluid at $0.1 \mathrm{~m}^{3} \mathrm{~h}^{-1}$ compared with DI.

Figure 7 shows the variation of thermal conductivity measured experimentally with different volume concentration of silica nanofluids with GA surfactant. The data are based on the comparison of experimental data and theoretical data calculated from Maxwell theory. Based on the experimental data, it is observed that the thermal conductivity increased with increasing silica content. Incorporation of GA as a surfactant in DI reduced agglomeration of the nanoparticles and 
influenced the stability of the nanofluids. Increase in stability and amount of silica ultimately results in an increase in conductivity. Based on Figure 7, increasing trend is insignificant in the case of theoretical values. This is because stability of nanoparticles has not been considered in the Maxwell theory since the theory is only considered thermal conductivity volume fraction of the particles and fluids.

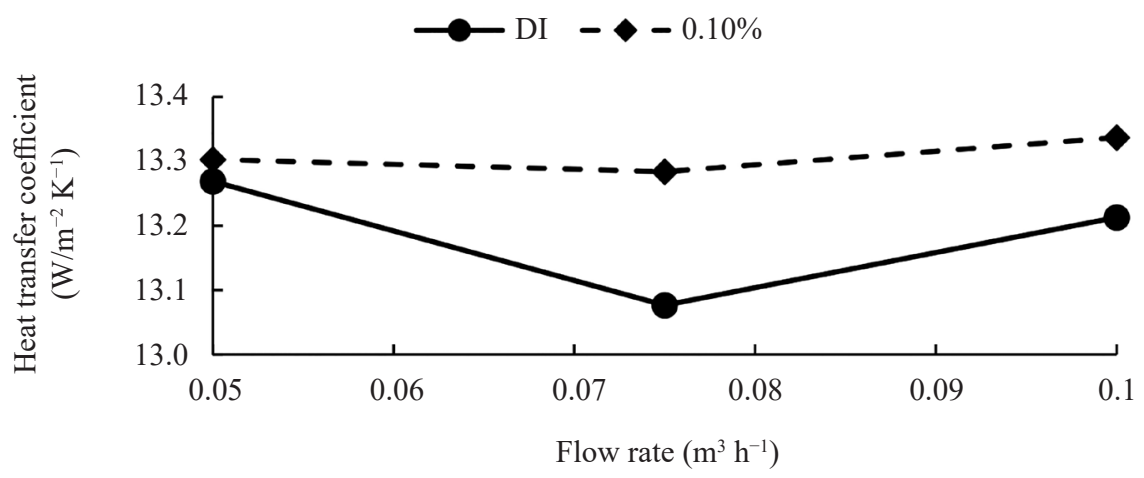

Figure 6: Heat transfer coefficient of DI and nanofluids at a constant power $(20 \mathrm{~W})$.

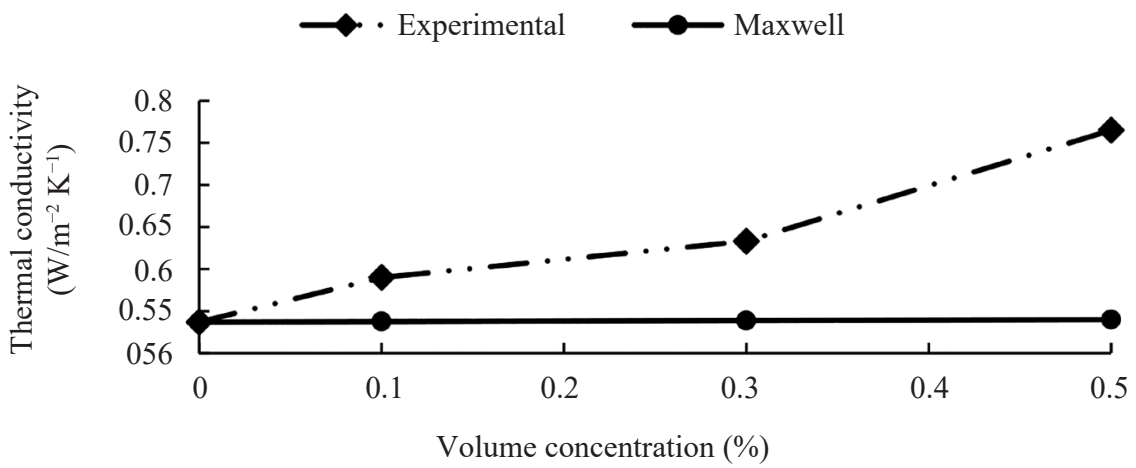

Figure 7: Experimental data on the thermal conductivity of silica nanofluids with GA surfactant measured at different volume concentrations of silica. Theoretical data are based on Maxwell theory.

Thermal conductivity enhancement of nanofluid are measured to know the ability of nanofluid to absorb, transfer and release heat in a system. Based on the result of thermal conductivity in Table 1, it is proven that silica nanofluids with GA surfactant possessed better thermal conductivity than DI and capable enough to substitute conventional fluid used in heat transfer system. 
Table 1: Thermal conductivity enhancement of DI and silica nanofluids with GA.

\begin{tabular}{lcc}
\hline Fluids & Thermal conductivity $\left(\mathrm{W} \mathrm{m}^{-2} \mathrm{~K}^{-1}\right)$ & Thermal conductivity enhancement $(\%)$ \\
\hline DI & 0.537 & 0 \\
$0.1 \%$ silica & 0.59 & 9.87 \\
$0.3 \%$ silica & 0.63 & 17.88 \\
$0.5 \%$ silica & 0.76 & 42.46 \\
\hline
\end{tabular}

\section{CONCLUSION}

Based on the experimental work, a number of conclusions can be made. Silica nanofluid with GA indicated less sedimentation compared to nanofluid containing CI and DBSA surfactants. With addition of silica, the fluid contact surface temperature and thermal resistance of nanofluids at various flow rate reduced compared to that of DI. Higher HTCs is observed for nanofluids compared to DI because of their higher thermal conductivity. Comparison of experimental and theoretical data calculated from Maxwell theory indicated that thermal conductivity increased with increasing silica content with more obvious trend shown by experimental data. The highest thermal conductivity enhancements which is $42 \%$ is shown by $0.5 \mathrm{vol} \%$ of silica and GA used in the nanofluid.

\section{ACKNOWLEDGEMENTS}

The authors gratefully acknowledge the funding received from Universiti Sains Malaysia (USM) in conducting this experimental study. This research project was supported by a Short-term Grant (no. 6315193), USM.

\section{REFERENCES}

1. Zainal, S. et al. (2016). ANSYS simulation for Ag/HEG hybrid nanofluid in turbulent circular pipe. J. Adv. Appl. Mech., 23, 20-35.

2. Choi, S. U. \& Eastman, J. A. (1995). Enhancing thermal conductivity of fluids with nanoparticles. Paper presented at the Proceedings of the ASME International Mechanical Engineering Congress and Exposition, San Francisco, 12-17 November.

3. Ding, Y. et al. (2006). Heat transfer of aqueous suspensions of carbon nanotubes (CNT nanofluids). Int. J. Heat Mass Trans., 49(1-2), 240-250, https://doi. org/10.1016/j.ijheatmasstransfer.2005.07.009.

4. Lee, S. et al. (1999). Measuring thermal conductivity of fluids containing oxide nanoparticles. J. Heat Trans., 121(2), 280-289. 
5. Wang, X. et al. (1999). Thermal conductivity of nanoparticle-fluid mixture. J. Thermophys. Heat Trans., 13(4), 474-480.

6. Abbasi, S. et al. (2016). Experimental investigation of the rheological behavior and viscosity of decorated multi-walled carbon nanotubes with $\mathrm{TiO}^{2}$ nanoparticles/ water nanofluids. J. Therm. Anal. Calorim., 123(1), 81-89, https://doi.org/10.1007/ s10973-015-4878-4.

7. Srinivas, V. et al. (2016). Nanofluids with CNTs for automotive applications. Heat Mass Trans., 52(4), 701-712.

8. Pradhan, S. et al. (2016). Effect of sonication on particle dispersion, administered dose and metal release of non-functionalized, non-inert metal nanoparticles. J. Nanopart. Res., 18(9), 285-297, https://doi.org/10.1007/s11051-016-3597-5.

9. Kiong Kiu, S. S. K. et al. (2017). Tribological investigation of graphene as lubricant additive in vegetable oil. J. Phys. Sci., 28(Supp. 1), 257-267.

10. Hung, T. C. et al. (2012). Heat transfer enhancement in microchannel heat sinks using nanofluids. Int. J. Heat Mass Trans., 55, 2559-2570, https://doi.org/10.1016/j. ijheatmasstransfer.2012.01.004.

11. Maxwell, J. (1881). A treaties on electricity and magnetism. London: Clarendon Press.

12. Rudresha, S. \& Kumar, V. (2014). CFD analysis and experimental investigation on thermal performance of closed loop pulsating heat pipe using different nanofluids. Int. J. Adv. Res., 2(8), 753-760.

13. Jia, H., Jia, L. \& Tan, Z. (2013). An experimental investigation on heat transfer performance of nanofluid pulsating heat pipe. J. Therm. Sci., 22(5), 484-490, https://doi.org/10.1007/s11630-013-0652-8. 